\title{
Activated carbon derived from peat soil as a framework for the preparation of shape- stabilized phase change material
}

\begin{abstract}
This work focuses on the preparation of AC (activated carbon) through a physical activation method using peat soil as a precursor, followed by the use of the AC as an inorganic framework for the preparation of SPCM (shape-stabilized phase change material). The SPCM, composed of n-octadecane as the core and AC pores as a framework, was fabricated by a simple impregnation method, with the mass fraction of n-octadecane varying from 10 to 90 wt. \%. The AC has a specific surface area of $893 \mathrm{~m}^{2} \mathrm{~g}^{-1}$ and an average pore size of $22 \AA$. The field emission scanning electron microscope images and nitrogen gas adsorptiondesorption isotherms shows that the n-octadecane was actually encapsulated into the AC pores. The melting and freezing temperatures of the composite PCM (phase change material) were $30.9{ }^{\circ} \mathrm{C}$ and $24.1^{\circ} \mathrm{C}$, respectively, and its corresponding latent heat values were $95.4 \mathrm{Jg}^{-1}$ and $99.6 \mathrm{Jg}^{-1}$, respectively. The composite shows a good thermal reliability, even after 1000 melting/freezing cycles. The present research provided a new SPCM material for thermal energy storage as well as some new insights into the design of composite PCM by tailoring the pore structure of AC derived from peat soil, a natural resource
\end{abstract}

Keywords: Phase change material; Activated carbon; Thermal energy storage; $\mathrm{n}$ Octadecane; Shape-stabilized phase change materials 